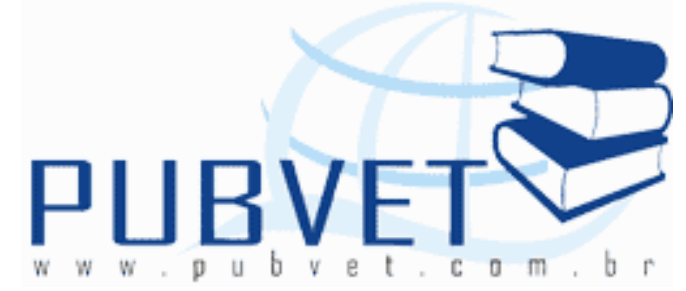

PUBVET, Publicações em Medicina Veterinária e Zootecnia.

\title{
A lucratividade na pecuária: atividades de bovinocultura de corte e de leite
}

Nelson Junior Freitas Nunes ${ }^{1}$, Sergio Cavagnoli Guth², Maria Emilia Camargo ${ }^{3}$, Marta Elisete Ventura da Motta ${ }^{4}$, Maria Teresa Martiningui Pacheco ${ }^{5}$, Rosecler Maschio Gilioli ${ }^{4}$, Walter Priesnitz Filho ${ }^{6}$

${ }^{1}$ Bacharel em Ciências Contábeis - Universidade de Caxias do Sul, RS

${ }^{2}$ Mestre em Economia - Universidade de Caxias do Sul,

${ }^{3}$ Doutora em Engenharia de Produção - PPGA - Universidade de Caxias do Sul

${ }^{4}$ Doutoranda em Administração - PPGA - Universidade de Caxias do Sul

${ }^{5}$ Mestranda em Administração - PPGA - Universidade de Caxias do Sul

${ }^{6}$ Mestre em Ciências da Computação - CTISM - Universidade de Santa Maria, RS

\section{Resumo}

O presente artigo destaca a importância das informações contábeis aos produtores rurais e às projeções futuras para a pecuária de corte e leite. Aborda fatos históricos e a evolução da pecuária brasileira e do Rio Grande do Sul, através de duas raças, a holandesa como produtora de leite e a Aberdeen Angus como produtora de carne, em sistema intensivo de produção. A pesquisa usou análise de referenciais técnicos sobre bovinocultura de leite e de corte, e realizou um estudo de caso numa amostragem de trinta bovinos de corte e dez de leite. Verificou-se a importância destas atividades ao setor 
primário do Brasil e sua representatividade no exterior. As bovinoculturas foram analisadas e os resultados comparados, através da margem de contribuição operacional, identificando-se como a mais lucrativa, das atividades, destacando-se a bovinocultura leiteira como mais lucrativa 19,32\% em sistema intensivo de produção pecuária de bovinos. Analisando as bovinoculturas de corte e leiteira em sistema intensivo, pode-se verificar que ambas as bovinoculturas são lucrativas e consorciadas podem trazer benefícios aos produtores rurais.

Palavras-chave: bovinocultura de corte, bovinocultura de leite, lucratividade.

\section{Abstract}

This article highlights the importance of accounting information to farmers and future projections for the beef cattle and milk. Discusses historical facts and the evolution of Brazilian cattle and of Rio Grande do Sul, through two breeds, the Dutch as a producer of milk and the Aberdeen Angus beef producer, intensive production system. The research used referential analysis about technical and milk cattle cutting, and conducted a case study on a sampling of ten thirty cattle and milk. Noted the importance of these activities to the primary sector of Brazil and its representation abroad. The bovinoculturas were analyzed and the results compared, through operating contribution margin, identifying itself as the more profitable activities, highlighting the most profitable dairy as intensive system in 19.32 livestock production of cattle. Analyzing the cutting dairy in bovinoculturas and intensive system, you can check that both are bovinoculturas lucrative Consortium and can bring benefits to rural producers.

Keywords: Beef cattle, milkmaid cattle, profitability.

\section{INTRODUÇÃO}

A pecuária pode ser considerada importante para toda a humanidade, tanto como forma de alimento, satisfazendo uma das principais necessidades humanas para a sobrevivência, como na forma de expansão e melhoramento 
da economia mundial. Tem importante função social gerando impostos, renda e emprego na atividade rural, e mantendo o homem no campo, pois a pecuária necessita de mão-de-obra.

É necessário, porém, que a atividade pecuária seja tratada como uma empresa, assim o agropecuarista necessita buscar a eficiência em seu trabalho, ele precisa estar capacitado, organizado e planejado para proporcionar obtenção de resultados positivos na exploração agropecuária da propriedade rural, pois sem uma boa gestão do negócio, os resultados podem ser negativos. Aliás, diz muito bem Nepomuceno (2004, p. 16), "Conhecimento é a chave do negócio." Sabe-se que "quase sempre o êxito de pequenos produtores decorre de um certo arranjo de diversificação que Ihes permita compensar perdas em uma atividade sob condições climáticas desfavoráveis em certos anos, com ganhos em outras que não dependam das mesmas condições." (NEPOMUCENO, 2004, p. 15).

O presente trabalho trata de duas atividades rurais, a bovinocultura de corte e bovinocultura leiteira. A primeira, é a exploração de bovinos de corte, que tem como seu principal produto a carne, que é um alimento de grande prestígio nacional e internacional, e destaca sua importância positiva na balança comercial. A segunda atividade é a bovinocultura leiteira que tem como produto principal o leite do qual após processo industrial transforma-se em vários subprodutos derivados do leite, este produto é um alimento de muita importância nutricional e cultural, e tem valor econômico e financeiro significativo na economia nacional.

A atividade rural é atividade econômica e, como tal, requer controle financeiro e acompanhamento específico. A Contabilidade Rural, por isso, deve ser um instrumento útil ao conhecimento dos resultados por atividade no setor rural ao alcance de seus usuários.

Diante deste contexto, para que o pecuarista consiga produzir mais e melhor, tanto carne, como leite é necessário que ele tenha noção dos custos e despesas, da margem de contribuição de seu produto, quais são os investimentos que Ihe beneficiarão, e qual a sua lucratividade. Com esse 
intuito, a pesquisa realizou um estudo de caso, elencando as receitas e custos de produção, compararam-se as duas atividades da bovinocultura intensiva e através do resultado operacional anual de cada atividade, comparou-se a margem de contribuição, identificando a mais lucrativa para a empresa rural.

\section{FUNDAMENTAÇÃO TEÓRICA}

A revisão da literatura está voltada para os temas de relevância deste estudo, que são a pecuária, a importância da pecuária para o setor primário, as projeções para as atividades pecuárias, a bovinocultura de corte e por fim, a contabilidade rural na pecuária

\subsection{PECUÁRIA}

Afirma Marion (2004, p. 20) que "Pecuária é a arte de criar e tratar gado, que são animais geralmente criados no campo, para serviços de lavoura, para consumo doméstico ou para fins industriais e comerciais. Como exemplos de gado podem-se citar: bovinos, bubalinos, caprinos, eqüinos, ovinos, muares, etc." Assim, os bovinos podem servir às seguintes finalidades: trabalho, reprodução, corte e leite.

A história da pecuária brasileira iniciou-se pela década de 30 do século XVI, através da instalação na colônia, da agromanufatura do açúcar. Desde o início da colonização, a produção colonial voltou-se para os interesses metropolitanos e desta forma, outras atividades econômicas foram marginalizadas. (HISTÓRIANET, 2006).

O latifúndio monocultor, apoiado no trabalho escravo africano, formou a base do Antigo Sistema Colonial. Na verdade, o primeiro nível de acumulação de capitais fazia-se com o tráfico de escravos, responsável por grande lucro para Portugal, já percebido antes do início da colonização brasileira, apesar de definidas as atividades economicamente rentáveis, o desenvolvimento do engenho exigiu atividades complementares, consideradas secundárias, porém 
fundamentais, sem as quais seria impossível a produção açucareira. Nesse sentido destacaram-se duas atividades: a pecuária e a agricultura de subsistência. (HISTÓRIANET, 2006).

As primeiras cabeças a chegarem ao Brasil, vieram das Ilhas de Cabo Verde, em 1534, para a capitania de São Vicente. Em 1550, Tomé de Sousa mandou uma caravela a Cabo Verde para trazer um novo carregamento, desta vez para Salvador. Da capital da colônia o gado dispersou-se em direção a Pernambuco e daí para o nordeste, principalmente Maranhão e Piauí. (HISTÓRIANET, 2006).

A partir do início do século XVII, a atividade criatória torna-se mais independente, ocupa terras cada vez mais para o interior, pois o desenvolvimento dos rebanhos exige grandes extensões de terras para as pastagens. Os rebanhos se destinam ao mercado interno, principalmente aos engenhos, porém se tornam atividades separadas, e as feiras de gado tornamse o elo entre ambos os interesses. A primeira feira realizou-se na Bahia em 1614. É nesse momento que a pecuária pode ser vista como um fator de povoamento do interior. (HISTÓRIANET, 2006).

\subsubsection{Pecuária Brasileira no Mundo}

A globalização estimulou a modernização da pecuária bovina nacional (carne e leite), tornando-a mais competitiva nacional e internacionalmente, devido à maior concorrência não só entre países, mas também entre outras fontes de proteínas, principalmente carnes de frango e suína. (CORRÊA et al., 2006).

$\mathrm{Na}$ pecuária de corte observa-se que o Brasil tem o maior rebanho bovino comercial do mundo, com cerca de 204,7 milhões de cabeças, segundo o IBGE. Entretanto, o maior rebanho do mundo encontra-se na Índia, com 336,9 milhões de animais, porém, lá esses animais são considerados sagrados, não sendo utilizados para alimentação humana e, por tanto, sem finalidade comercial. A China tem o segundo maior rebanho efetivo, com cerca de 143,4 milhões de cabeças, seguida por Estados Unidos (98,8 milhões), Argentina 
(50,9 milhões) e Austrália (29,1 milhões). A União Européia que congrega 25 países conta com 85,7 milhões de cabeças. (CORRÊA, 2006).

As exportações brasileiras de carne bovina, mesmo com o embargo internacional, atingiram recorde histórico no primeiro semestre de 2006. Além disso, as indústrias estão conseguindo obter melhores preços para a mercadoria. "Os valores estão melhores, algo absolutamente fundamental para o setor, que também tem de enfrentar a crise cambial.", avalia o presidente da Abiec, Marcus Vinícius Pratini de Moraes. (CORRÊA, 2006, p. 23).

\subsubsection{Pecuária no Rio Grande do Sul}

No Rio Grande do Sul a pecuária teve início com a influência espanhola, sendo uma das suas maiores contribuições em termos econômicos, à introdução de bovinos no Rio Grande do Sul, segundo o Rio Grande (2006). Pode-se verificar que sem a participação espanhola a pecuária, que seria a base da economia gaúcha durante o século XIX e início do $X X$, teria se difundido.

Durante o século XVII, quando formaram suas reduções com os índios guaranis, os jesuítas se preocuparam em dispor de grandes rebanhos de gado para garantir a alimentação de seus tutelados. Graças a isso e a ameaças de vinganças divinas é que eles mantiveram os índios reunidos. Quando os jesuítas foram expulsos, o gado ficou na região e se proliferou, tornando-se uma atração para portugueses e espanhóis. Os paulistas das bandeiras e os lagunenses que primeiro penetraram em território gaúcho o faziam em busca de gado. (RIO GRANDE, 2006).

\subsection{IMPORTÂNCIA DA PECUÁRIA PARA O SETOR PRIMÁRIO}

A pecuária é uma das atividades do setor primário, entre outras como a agricultura e extrativismo, são basicamente pertencentes ao setor rural, onde temos a presença do homem do campo, que são pessoas envolvidas no setor primário. (HISTÓRIANET, 2006). Portanto, a pecuária desenvolveu-se impulsionada por novas técnicas de pesquisas para aumentar e melhorar a 
produtividade pecuária. Utilizando-se complementos alimentares, insumos para a pecuária, tecnologia genética e mecanização, que são fatores que estão ligados diretamente com a economia como uma corrente, onde o primeiro elo da corrente é o setor primário, ou seja, o primeiro.

O setor primário é responsável por 17,4 milhões de pessoas trabalhando e gerando renda, pois é um dos setores que mais ocupa mão-de-obra, segundo pesquisa do Instituto Brasileiro de Geografia e Estatística (IBGE, 2003), e que mais rapidamente responde aos investimentos realizados.

A agricultura e pecuária serviram como planejamento estratégico para um dos planos econômicos mais recentes do Brasil, como estabilizador econômico, em 1994 com o Plano Real, pois o agronegócio é responsável por $27,87 \%$ das exportações, e a pecuária de corte coloca o Brasil como maior exportador mundial de carne bovina, segundo dados da FARSUL do ano de 2006.

O PIB do agronegócio obteve um pequeno declive nos dois últimos anos fechando 2005 com 27,87\%, sendo que em 2003 o PIB alcançou 30,58\%, o maior percentual adquirido nos últimos anos. A pecuária contribuiu com $8,27 \%$ do PIB do agronegócio em 2005.

Segundo dados da FARSUL (2006), "o Brasil destaca-se no cenário internacional como grande exportador, e a pecuária tem reconhecida participação neste processo sendo responsável por 8,27\% das exportações."

\subsection{PROJEÇÕES PARA AS ATIVIDADES PECUÁRIAS}

A tendência no sistema de carnes é a segmentação do mercado consumidor, pois se devem levar em consideração as diferenças de renda, idade, tamanho e ciclo de vida da família; região geográfica; alternativas de compra, conveniência de produtos e outros aspectos dentre as classes sociais. Portanto, há uma enorme variedade de segmentos de mercado: há quem prefira carne magra, carne marmorizada, filé mignon de um boi de 25 arrobas mais velho, carne com osso, boi ecologicamente correto, que deve ser mais bem explorada. (EUCLIDES FILHO, 2000). 
Tais alterações mercadológicas forçarão os produtores, e demais envolvidos na cadeia produtiva do leite e da carne bovina, a trabalhar em conjunto e de forma mais agressiva junto ao consumidor final. Isto poderá ocorrer através de campanhas de conscientização sobre o produto, formas de prepará-lo, benefícios à saúde, entre outros, além, é claro, da especialização nos diferentes segmentos de mercado.

Tudo parece indicar que a demanda global para produtos de origem animal continuará a crescer. $O$ desafio desta demanda e de gerar prosperidade para as indústrias da pecuária, é construir uma estrutura comercial que permita o acesso livre e aberto do gado, garantindo a proteção à saúde animal e humana com base em princípios de ciência bem fundamentada e não na ciência política, e de forma alguma na ficção científica. Os produtores e fazendeiros e indústrias de processamento responderão fazendo uso das novas tecnologias para desenvolver e comercializar produtos que beneficiarão os consumidores, satisfazendo sua demanda crescente por conveniência, segurança e saúde. (EUCLIDES FILHO, 2000).

Deve-se dar uma atenção especial para o mercado interno, pois este possui um grande potencial de crescimento, o que falta é um verdadeiro "arranjo" na política e economia do país para que se possibilite uma melhor distribuição de renda, conseqüentemente, uma melhor qualidade de vida para as classes sociais menos privilegiadas. Estudos indicam que quando há um aumento na renda per capita, as pessoas têm mais disposição para gastar com alimentos, este fator é de especial importância nos países de renda média baixa, onde $25 \%$ ou mais de qualquer aumento em receita é gasto em alimentos.

\subsection{BOVINOCULTURA DE CORTE}

A bovinocultura trata de uma atividade que está dividida em duas linhas, podendo ser executadas juntas ou não. Uma é a criação de gado comercial e a outra de gado elite, sendo que a primeira tem com principal objetivo a produção de carne bovina de qualidade para a alimentação humana, além de 
fornecer matéria-prima para a indústria farmacêutica, de cosmético, de calçado, de roupas, de rações, entre outras. Já a criação de gado elite tem como foco central à produção de matrizes e reprodutores para a criação de gado comercial e elite. (MARION, 2004, p. 21).

\subsubsection{Especialização das empresas pecuárias de corte}

Segundo Marion (2004, p. 21), "A produção da pecuária de corte pode ser dividida em três fases distintas, pelas quais passa o animal que se destina ao abate." Segundo o especialista,

Cria - A atividade básica é a produção e venda de bezerros que só serão vendidos após o desmame, normalmente a matriz (em época de boa fertilidade) produz um bezerro por ano.

Recria - A atividade básica é a partir do bezerro adquirido, a produção e venda de novilho magro para engorda.

Engorda - A atividade básica é a partir do novilho magro adquirido da produção para engorda e venda do novilho gordo, que é a última fase, pode ser feita a pasto ou no confinamento. (MARION, 2004, p. 21).

São, enfim, fases distintas na atividade pecuária de corte pelas quais passa o animal que se destina ao abate. A atividade cria-recria cai acentuadamente à medida que aumenta o tamanho da empresa, notadamente a cria. Por outro lado, a atividade cria-recria-engorda (sistema integrado), principalmente a de engorda cresce à medida que aumenta o tamanho da empresa. (MARION, 2004, p. 22).

\subsubsection{Sistemas de produção}

Quanto aos sistemas de produção (manejo) do bovino podem ser divididos basicamente em extensivo, semi-intensivo e intensivo. 
Sistema extensivo - Geralmente, os animais são mantidos em pastos nativos ou cultivados, na dependência exclusiva dos recursos naturais. Esse sistema caracteriza-se por baixa lotação, variando em áreas contíguas sem planejamento adequado de lotação e disponibilidade de forragens. O manejo sanitário baseia-se simplesmente em calendários oficiais de vacinação da região em que está inserida a propriedade. 0 manejo zootécnico é ausente ou pouco presente, não se preocupando com o suprimento de forragem no período adverso do ano (seca). É um sistema utilizado ainda em áreas recém-desbravadas, onde a produção de forrageira exerce forte pressão sobre os recursos naturais. (MARION, 2004, p. 20).

Sistema semi-intensivo - Com a inviabilidade técnica/econômica do sistema anterior devida à degradação das forrageiras ou pastagens, o pecuarista que pretende manter-se na atividade tem adotado esse método, em que se faz necessária a implantação de forrageiras, as quais sofrem um pastoreio racional, através de algumas subdivisões das pastagens, o que leva a uma maior capacidade de suporte por unidade de área. Há um manejo mais adequado do rebanho; além das vacinações obrigatórias, há vermifugação, mineralização e um acompanhamento zootécnico do rebanho. As pastagens / forrageiras recebem normalmente corretivos de solo (calcário) e adubação química, desde níveis baixo até suprimento de nutrientes. (MARION, 2004, p. 20).

Sistema intensivo - Com aumento da população e, conseqüentemente, com a redução da área útil com o desejo de obter maior produtividade, aumentando a rentabilidade, com o desenvolvimento tecnológico e da assistência técnica, se atinge paulatinamente o sistema intensivo que, entre outras medidas, consiste: [1] na formação de pastagens artificiais adequadamente adubadas e até irrigadas, com forrageiras 
adequadas à região, propiciando a divisão dos pastos para o estabelecimento de rodízio (permite repouso e recuperação das pastagens). [2] Melhoria tanto das condições de alimentação (arraçoamento, sal, minerais, entre outros), associando pasto + suplementação, pasto + confinamento, ou confinamento, como da ordem higiênico sanitária, o que só foi possível pela redução da distância entre o curral e o rebanho. [3] Na introdução de novas raças produtivas, adequadas à região, em substituição aos gados nativos. (MARION, 2004, p. 21).

\subsubsection{A Raça Aberdeen Angus}

O berço da raça Angus é a Escócia e seu nome foi tomado dos condados onde começou o seu desenvolvimento: Aberdeen e Angus. A história registra a existência dos "vacuns mochos pretos", no condado de Angus, antes do século XVI e sua origem é tão remota que não é possível precisar como e quando apareceram. Naquela época, tornaram-se famosos pela excelente qualidade de carne, rapidez de engorda e singular rusticidade. (ANGUS, 2006, p. 34).

O primeiro reprodutor Aberdeen Angus a entrar no Brasil foi o touro Menelik, em 1906, da criação de Felix Buxareo y Oribe, do Uruguai. O touro foi importado pelo Sr. Leonardo Collares Sobrinho, de Bagé, município situado na Fronteira do Rio Grande do Sul com o Uruguai. Oito anos depois, o Visconde Ribeiro Magalhães importou cinco matrizes da Inglaterra, sendo ele também a registrar o primeiro produto nacional. (ANGUS, 2006).

Influenciada pelo desenvolvimento atingido nos países do Prata, a raça Angus se expandiu rapidamente no Rio Grande do Sul, como demonstram os registros $\mathrm{PO}$ e $\mathrm{PC}$, e o sucesso da comercialização de reprodutores machos e fêmeas, ANGUS, (2006).

O Aberdeen Angus se destaca entre as raças taurinas por reunir um maior número de características positivas que the assegura um excelente resultado econômico como gado de corte. O conjunto de suas características a torna uma raça completa. Possui bom volume, alto e de aspecto alongado, 
medianamente profundo, de formas ligeiramente arredondadas. Musculoso, com linha superior reta e inferior ligeiramente levantada na virilha. Muito limpo e livre de gordura em toda linha baixa. Quartos cheios com massas musculares sobressalentes que evidenciam um perfil algo convexo. Paleta firme e bem musculosa. Antebraços e pernas fortes, compridos e bem musculosos. Esqueleto forte e aprumos corretos, ANGUS, (2006).

Em comparação com outras raças, os Angus tem demonstrado que, nas mesmas condições alimentares, atinge mais cedo a puberdade e o estado de abate. A precocidade dos Angus reflete-se no abate de novilhos jovens, que, além de uma necessidade mercadológica, é fator fundamental de uma pecuária de retorno mais rápido. (ANGUS, 2006).

A tendência racial no momento para o Angus é animais de porte médio, mais profundos, portanto com maior capacidade de adaptação na criação extensiva, e essencialmente produtores de carne.

No fator longevidade e fertilidade, registros oficiais comprovam que as fêmeas Angus se mantêm férteis até uma idade avançada, gerando terneiros de porte médio, não muito pesados ao nascer. O peso varia entre 28 e 32 quilos nos machos e 25 a 30 quilos nas fêmeas. Esta característica permite a rápida recuperação do ventre, diminuindo o intervalo entre os partos e proporcionando maior número de crias. Inúmeros registros comprovam a existência de fêmeas com 19 anos que geraram 16 crias; 18 anos e 14 crias; 10 anos e sete crias e muitos outros. (ANGUS, 2006).

\subsection{A bovinocultura leiteira}

A bovinocultura leiteira trata-se de uma exploração agropecuária com ênfase na produção de leite e seus derivados, porém explora a parte reprodutiva com animais para reposição ou comercialização de gado de elite em plantéis da raça. (BANET, 2005).

Os sistemas de criação para gado de leite mais utilizados são três: extensivo, semi-intensivo e intensivo. A opção por um modelo ou outro depende de minuciosa análise de mercado, para avaliar a demanda, em 
quantidade e qualidade, do leite a ser produzido. A escolha de melhor sistema de criação dependerá também das condições econômicas do criador, do local e dos meios de produção disponíveis. Por exemplo, em regiões planas, com boas pastagens e chuvas bem distribuídas ao longo do ano, o sistema de produção extensivo pode ser mais vantajoso, desde que o valor da terra não seja muito alto. (BANET, 2005).

\subsubsection{Sistema extensivo}

O sistema extensivo de criação é mais usado com gado misto, sem padrão racial definido, e consiste em criar os animais soltos no pasto. Onde a pastagem natural é à base da alimentação e as instalações são simples. Quando completas, são constituídas por: estábulo de ordenha, curral de espera, curral de manobra, cochos para forragens e para minerais (saleiro), bebedouros, reservatório, esterqueiras, cercas para piquetes de pastagens com bebedouros e saleiro, mata-burros. (BANET, 2005).

A ordenha, em geral, é feita uma vez por dia, manualmente, no próprio curral ou no galpão, com a presença dos bezerros. (BANET, 2005).

Embora esse sistema ainda seja o mais usado pelos pecuaristas brasileiros, a sua produtividade é baixa, principalmente nos períodos de estiagem, pois as pastagens ficam fracas, reduzindo muito a produção, para menos de cinco litros por animal por dia, em média. (BANET, 2005).

\subsubsection{Sistema semi-intensivo}

O site sobre a bovinocultura leiteira (BANET, 2005) ensina que o sistema semi-intensivo de criação é mais usado para gado de melhor padrão racial. Consiste em manter o gado no pasto e reforçar a sua alimentação em regime de confinamento parcial, quando necessário, permitindo maior estabilidade de produção. Assim, a alimentação no pasto é complementada, por exemplo, com silagem ou capim picado na época de estiagem. Esse sistema exige instalações como as do sistema extensivo, porém acrescenta-se curral de alimentação com bebedouros e silos ou fenos para forragens. Nesse sistema, animais de 
qualidade com manejo adequado conseguem produzir até 18 litros por dia, em duas ordenhas.

\subsubsection{Sistema intensivo}

O sistema intensivo de criação é o mais recomendado para gado de alto padrão racial. Consiste em criar os animais de elevada produção (acima de 20 litros por dia), permanentemente confinados no próprio estábulo de ordenha ou em galpões, dependendo da modalidade de estabulação a ser adotada, com manejo extremamente controlado. As benfeitorias são quase as mesmas do sistema semi-intensivo, acrescentados galpões de estabulação livre e reservatórios. (BANET, 2005).

A grande vantagem do sistema intensivo de criação consiste na eficiência do manejo e no conseqüente aumento da produtividade, pois o alimento pode ser produzido em áreas menores, armazenado e fornecido durante todo o ano.

Os animais são separados em instalações próprias, em lotes, de acordo com a idade e a fase de produção. Assim, bezerras, novilhas, vacas secas e vacas em produção ficam separadas. Esse sistema facilita a produção de leite no caso de grandes rebanhos, permitindo produção estável, sem oscilações de safra e entressafra. No sistema intensivo de criação, há dois modos de estabulação: convencional e estabulação livre.

No modo convencional de confinamento, as vacas têm acesso, na maior parte do tempo às baias individuais, uma ao lado da outra. A contenção dos animais é feita com canzis de madeira onde tubos metálicos chumbados diretamente no piso de concreto. A alimentação pode ser dada em cochos situados ao longo do corredor central. As canaletas de limpeza (pisos de vigotas de concreto ou piso ripado) ficam nas laterais do galpão, permitindo a higiene e drenagem rápida da área quando os animais vão para um piquete tomar sol. A ordenha é feita no próprio local em que as vacas ficam estabuladas. Em geral, o pé direito do galpão deve ser de, no mínimo, três metros. (BANET, 2005). 
A estabulação livre é o modo de confinamento mais moderno no sistema intensivo de produção. Nele, os animais são alojados em galpões, onde podem circular pelos corredores para se alimentar, beber água ou descansar.

Em geral, o concentrado e as fontes de minerais são misturados de forma balanceada ao volumoso, constituindo a ração total, que pode ser fornecida diretamente sobre 0 piso. Esse modo de confinamento é recomendado para rebanhos com mais de cinqüenta vacas, porque facilita o manejo. (BANET, 2005).

\subsubsection{A Raça Holandesa}

Pouco se sabe sobre a origem da raça Holandesa, ou frieshollands veeslay, ou ainda frísia holandesa, havendo anotações que vão até o ano 2000 A.C. Alguns afirmam que foi domesticada a 2.000 anos nas terras planas e pantanosas da Holanda setentrional e da Alemanha. Eram animais de origem grega, de acordo com ilustrações antigas, o que causa maior dúvida sobre sua formação. No Brasil não foi estabelecida uma data de introdução da raça Holandesa no Brasil. Paulino Cavalcanti (1935) cita que "segundo os dados históricos, referentes à nossa colonização, presume-se que o gado Holandês foi trazido nos anos de 1530 a 1535, período no qual o Brasil foi dividido em capitanias hereditárias".

O Herd-Book começou a funcionar em 1935, com o macho "Colombo St. Maria" de Francisco Lampréia, RJ. E "Campineira", de Vicente Giaccaglini/SP. (GADOHOLANDES, 2005).

Até o início de 1980, o Brasil foi considerado o detentor do maior rebanho mundial de HVB (Holandês Vermelho Branco), mas o efetivo foi decrescendo, ano após ano, por falta de disponibilidade de reprodutores VB (Vermelho Branco) com provas genéticas comprovadas e também pela não aceitação das cobrições de vacas VB por touros PB (Preto Branco). A abertura para uso de reprodutores PB sobre vacas VB somente aconteceu por volta de 
1984 desde que o reprodutor fosse portador de gene recessivo para pelagem VB. (GADOHOLANDES, 2005).

As holandesas, segundo o site GADOHOLANDES (2005), apresentam as seguintes características: idade para a primeira cobertura fica entre 16 a 18 meses. A idade para o primeiro parto: 25 a 27 meses. A duração da gestação: 261 dias a 293 dias e o intervalo entre partos: 15 a 17 meses.

\subsection{CONTABILIDADE RURAL NA PECUÁRIA}

Com a evolução da tecnologia e a busca de aprimoramento dos produtos agropecuários, o produtor rural também necessita desenvolver cada vez mais técnicas gerenciais tanto na área de produção como também no patrimônio econômico e financeiro de sua propriedade.

A pecuária pode adotar métodos de gestão profissional no campo e dessa forma melhorar sua exploração dos seus recursos, com a finalidade de obter de forma ágil e segura o retorno do seu investimento, e adquirir maior lucratividade dentro da atividade desenvolvida. Crepaldi (1998, p. 15) acrescenta que "hoje, no mundo empresarial, todos sabem que o segredo para a competitividade em longo prazo é a satisfação total do cliente [...] para que se tornem totalmente voltadas para o cliente, está a informação gerencial."

Desta forma, a contabilidade pode desempenhar um importante papel como ferramenta gerencial, através de informações que permitam o planejamento, o controle e a tomada de decisões, transformando as propriedades rurais em empresas com capacidade para acompanhar a evolução do setor, controle dos custos, diversificação de atividades e comparação de resultados.

O próprio produtor rural, pessoa física ou jurídica, com atividade econômica organizada de bens e serviços é o empreendedor rural, e o estabelecimento é o local onde se desenvolve essa atividade, que é a propriedade rural, segundo Marion (2004, p. 20) "empresas rurais são aquelas que exploram a capacidade produtiva do solo por meio do cultivo da terra, da criação de animais e da transformação de determinados produtos agrícolas". 
O conceito de empresa rural aborda a exploração da terra e da criação dos animais como fonte de renda. Partindo desses conceitos, as atividades rurais classificam-se em três grupos distintos:

- Produção Vegetal - Atividade Agrícola;

- Produção Animal - Atividade Zootécnica;

- Indústrias Rurais - Atividade Agroindustrial.

A Instrução Normativa SRF no 83, de 11 de outubro de 2001, interpretada por Marion (2004), em seu artigo $2^{\circ}$ considera atividade rural:

a) a agricultura;

b) a pecuária;

c) a extração e a exploração vegetal e animal;

d) a exploração de atividades zootécnicas, tais como apicultura, avicultura, cunicultura, suinocultura, sericicultura, piscicultura e outras culturas animais;

e) a atividade de captura de pescado in natura, desde que a exploração se faça com apetrechos semelhantes aos da pesca artesanal (arrastões de praia, rede de cerca entre outros), inclusive a exploração em regime de parceria;

f) a transformação de produtos decorrentes da atividade rural, sem que sejam alteradas as características do produto in natura, feita pelo próprio agricultor ou criador, com equipamentos e utensílios usualmente empregados nas atividades rurais, utilizando-se exclusivamente de matériaprima produzida na área rural explorada. (MARION, 2004).

Dessa forma, nem todas as atividades desenvolvidas no meio rural são consideradas pela lei como sendo atividades rurais, é o caso da fabricação de bebidas alcoólicas e o beneficiamento de arroz em máquinas industriais.

O NCC (Novo Código Civil/2002), através do artigo 970 diz que "a lei assegurará um tratamento favorecido, diferenciado e simplificado ao empresário rural e ao pequeno empresário quanto à inscrição e aos efeitos daí decorrentes."

A obrigação do Registro ainda não estaria sendo cobrada pelo NCC em relação ao empresário rural e ao pequeno empresário, uma vez que não tendo 
registro, não é considerado empresário rural e como tal, imune á obrigação estabelecida pelo artigo 1.179 do NCC, que regulamenta a obrigatoriedade da escrituração contábil e elaboração anual do Balanço Patrimonial e Demonstração do Resultado do Exercício. (MARION, 2004).

Portanto, o empresário rural deve prevenir-se para o futuro, em sua forma de avaliar sua atividade. Para o produtor rural não ser "pego de surpresa", deve implantar a contabilidade em sua propriedade rural desde agora, antecedendo os acontecimentos que farão parte muito em breve de sua vida cotidiana.

Essa nova visão da potencialidade rural e valorização do produtor rural, assegurada pelo Código Civil 2002, vem a colaborar com gestores rurais fornecendo o correto procedimento de como administrar uma propriedade rural, também colocando em suas mãos uma melhor maneira de que ele e sua família venham adquirir cada dia mais crescimento e auto-sustentação para exercer as atividades no agronegócio brasileiro. (MARION, 2005).

Todas as atividades rurais por menores que elas sejam, requerem um controle eficiente, uma vez que os impactos das decisões administrativas são fundamentais para uma boa gestão. Um fato real que acontece hoje na maioria das propriedades rurais é que muitos dos serviços contábeis que são importantes instrumentos gerenciais não são utilizados por seus administradores ou proprietários. Muitas vezes, o produtor rural guarda em sua memória as informações, não anota os acontecimentos que são de extrema importância para a correta contabilização, de maneira que com o passar do tempo são esquecidos, e não calculados na hora da comercialização dos produtos.

Assim, na maioria das propriedades, os seus gestores não possuem condições para distinguir os resultados obtidos com suas atividades, os custos de produção em sua propriedade, verificar quais seriam os mais rentáveis, onde poderiam minimizar os custos de produção. Muitas vezes, o produtor rural não consegue distinguir o dinheiro que obteve com a venda do novilho, do recebido da venda do leite. Então, o controle de caixa da propriedade fica 
totalmente desorganizado, envolvendo também seu capital particular, dificultando ainda mais a contabilização de seus resultados.

Desta forma, deve ser realizado um trabalho de maneira clara e objetiva, para haver aceitação e entendimento por parte do pecuarista, isso para permitir que o mesmo perceba que esses recursos, trarão para ele e sua família uma comodidade e também poderão elevar o rendimento dos seus negócios.

A atividade rural seria mais bem gerenciada, se existissem informações contábeis como acontece com os outros setores, elaboradas e aplicadas no ramo da atividade rural. A contabilidade aplicada na atividade rural pode demonstrar toda a vida evolutiva da empresa, por isso é imprescindível que também na agropecuária, a contabilização dos fatos e sua estruturação sejam realizados com o perfeito conhecimento, não apenas técnico, mas também de sua atividade operacional, respeitando as peculiaridades da atividade.

As informações contábeis podem permitir ao empresário rural, conhecer melhor sua propriedade e suas atividades desenvolvidas, destacando-se alguns pontos importantes, como:

a) quais atividades produtivas ele desenvolve;

b) planejamento e controle das atividades exploradas;

c) ter as receitas e despesas evidenciadas para o desempenho do negócio;

d) o potencial de crescimento da propriedade e das atividades rurais;

e) destacar o retorno dos seus investimentos e principalmente saber qual o verdadeiro custo de produção.

Todas essas informações devem estar de forma clara e objetiva, com o intuito de abastecer o empresário rural com as instruções corretas e capaz de ajudá-lo no bom desempenho do agronegócio.

O empresário rural deve possuir a correta contabilização de sua atividade, sendo indispensável recorrer ao auxílio de um profissional contábil pois o mesmo terá melhores condições de elaborar relatórios específicos para sua propriedade e seu ramo de atividade, sabendo quais as tendências do 
mercado tanto interno quanto externo e buscando um aprimoramento e a diversificação de seus produtos com base nessas tendências.

A contabilidade deve assegurar ao empresário rural condições de sobreviver e garantir a competitividade no agronegócio, direcionando na tomada de decisões, possibilitando o aumento dos resultados econômicos.

Os resultados dos empreendimentos devem satisfazer ao empresário rural e permitir a ele seu espaço, em um mundo cada vez mais globalizado e com tantas novidades surgindo a todo tempo. Após, o empresário rural poderá perceber que a atividade rural unida com a contabilidade vem dando certo e que seu correto planejamento e controle irão the proporcionar ótimos resultados econômicos na pecuária bovina de leite e corte.

\section{METODOLOGIA}

Segundo Gil (2001, p. 19), pode-se definir "pesquisa como o procedimento racional e sistemático que tem como objetivo dar respostas aos problemas que são propostos." Para essa pesquisa, "a metodologia não só contempla a fase de exploração de campo como a definição de instrumentos e procedimentos para análise dos dados" (MINAYO, 2002, p. 43), sendo, portanto, elemento fundamental para a rigorosidade científica que se pretende dar ao tratamento das questões. Tratando-se de um procedimento racional, evidentemente, a pesquisa exigiu do operador o uso de métodos, processo e técnicas.

Esta pesquisa teve como objetivo "verificar a lucratividade por meio da margem de contribuição, comparando os resultados entre duas atividades pecuárias, a bovinocultura de corte (parte de engorda), raça Aberdeen Angus, e a leiteira (parte da produção de leite), raça holandesa." Para o estabelecimento de relações entre as variáveis realizou-se uma pesquisa descritiva que visou explicitar as características de uma determinada população (empresários do agronegócio) e estabelecer relações entre as 
variáveis. Quanto aos objetivos esta pesquisa se caracteriza como pesquisa exploratória e descritiva. (BELLO, 2004).

Quanto aos procedimentos técnicos utilizou-se a pesquisa bibliográfica através da consulta em livros, jornais, revistas e artigos da Internet. A pesquisa foi operacionalizada através do estudo de caso que, conforme definição de Diehl (2002, p. 87), "implica estudo profundo e exaustivo de um ou de poucos objetos, de maneira que permita o seu amplo e detalhado conhecimento por sua flexibilidade e por sua ampla aplicabilidade." Ou seja, o estudo de caso foi realizado em propriedades rurais do estado do Rio Grande do Sul, e para a coleta dos dados foram, realizadas entrevistas semiestruturadas, no mês de novembro de 2006 , com os proprietários.

\section{APRESENTAÇÃO E DISCUSSÃO DOS RESULTADOS - ESTUDO DE CASO}

As empresas que participaram da pesquisa utilizam o sistema intensivo de produção de leite e carne. A capacidade produtiva das bovinoculturas é analisada num período de um ano, onde o número de animais é diferente, mas equivalente. O potencial de produção deste tem capacidade de sustentar a mesma quantidade de bovinos por metro quadrado.

A produção de carne utiliza um número maior de animais, pois estes são abatidos, posteriormente, são adquiridos novos animais em mesmo número para ocupar o lugar dos que foram abatidos. Este processo ocorre três vezes no ano, ou seja, três safras, na propriedade objeto de estudo deste trabalho, totalizando trezentos bovinos de corte. A bovinocultura de leite mantém os mesmos animais durante o período de estudo, totalizando cem bovinos no ano. 


\subsection{CARACTERIZAÇÃO DAS EMPRESAS PESQUISADAS}

\subsubsection{CABANHA AMOR À TERRA}

A pesquisa iniciou-se na fazenda Cabanha Amor à Terra. A fazenda tem como principal atividade rural a exploração pecuária da bovinocultura de corte com a finalidade reprodutiva de gado de elite, PO (puro de Origem) e PC (Puro por Cruza), em sistema intensivo, onde os animais desprovidos da certificação PO e PC são confinados e engordados para abate com média de 18 meses de idade.

Quanto à mão-de-obra, há um funcionário que dispensa aproximadamente 1 hora por dia nesta atividade, distribuindo o tempo restante na execução de outras atividades da empresa. essa mão-de-obra não precisa ser especializada, nem precisa dedicação de tempo integral nas tarefas do gado, sendo usual o rateio.

A avaliação técnica para seleção e certificação dos bovinos PO e PC é muito rigorosa, sendo desclassificados muitos animais, os quais são remanejados novamente na propriedade.

Os machos são castrados e confinados para engorda e abate. As fêmeas são classificadas na propriedade para matriz de embriões.

Os machos castrados são readaptados ao sistema de confinamento a cocho, com alimentação a base de silagem de milho a 56,21\% e concentrado $43,79 \%$ onde o concentrado é à base de resíduos $42,49 \%$, de soja, resíduo de milho e resíduo de trigo, com sal branco $0,40 \%$ e minerais $0,40 \%$, além de uréia $0,50 \%$ - um composto nitrogenado que é convertido em proteína para os ruminantes.

A quantidade de alimento é relacionada conforme o peso vivo dos animais, $1 \%$ do peso vivo dos bovinos, conforme pode ser observado no Quadro 1. 
Quadro 1 - Alimentação dos bovinos (media das três safras)

\begin{tabular}{|c|c|c|c|c|}
\hline Alimentação & Quantidade & $\%$ & $\begin{array}{l}\text { Preço kg - } \\
\text { R\$ }\end{array}$ & $\begin{array}{r}\text { Custo total } \\
\text { R\$ }\end{array}$ \\
\hline $\begin{array}{r}\text { Silagem de } \\
\text { milho }\end{array}$ & $5.935,77$ & 56,21 & 0,0187 & 111,23 \\
\hline Resíduos & $4.486,94$ & 42,49 & 0,20 & 897,38 \\
\hline Sal & 42,24 & 0,40 & 0,32 & 13,51 \\
\hline Mineral & 42,24 & 0,40 & 0,96 & 40,55 \\
\hline Uréia & 52,8 & 0,50 & 0,59 & 31,60 \\
\hline Total & $10.560,00$ & 100,00 & & $1.094,28$ \\
\hline
\end{tabular}

Fonte: elaborada pelos autores

O custo de aquisição dos alimentos é avaliado pelo custo da silagem (lavoura plantada, colhida e feita à silagem, inclusos custos de mão-de-obra e depreciação de máquinas e equipamentos) aproximadamente de $R \$ 1.112,30$ por hectare, conforme dados da Cargil (2006), e os concentrados são avaliados pelo custo de aquisição em silo de secagem e seleção de cereais, com preços de mercado uniformes aos três tipos de resíduos, de soja, de milho e de trigo.

Também são adquiridos novilhos magros de outras propriedades similares. O custo de aquisição dos animais é avaliado conforme o preço do kg vivo do novilho magro, estabelecido pelo mercado conforme Quadro 2.

A aquisição dos animais provindos da fazenda, objetos deste estudo seguem o mesmo padrão.

Quadro 2 - Aquisição dos animais (10 animais por safra)

\begin{tabular}{|r|r|r|r|}
\hline $\begin{array}{r}\text { Custo dos } \\
\text { novilhos }\end{array}$ & $\begin{array}{r}\text { Preço unitário } \\
\mathbf{R \$}\end{array}$ & $\begin{array}{c}\text { Preço/ kg } \\
\mathbf{R \$}\end{array}$ & $\begin{array}{r}\text { Preço Total } \\
\mathbf{R \$}\end{array}$ \\
\hline Outubro 2005 & 478,50 & 1,65 & $4.785,00$ \\
\hline Fevereiro 2005 & 480 & 1,60 & $4.800,00$ \\
\hline Junho 2005 & 470,25 & 1,65 & $4.702,50$ \\
\hline Anual & 476,25 & 1,63 & $14.287,50$ \\
\hline
\end{tabular}

Fonte: dados dos registros contábeis

O preço unitário é calculado pelo peso multiplicado pelo preço. Posteriormente, é feita uma média entre os novilhos. 
São realizadas três safras anuais com intervalos de 120 dias, quando os animais estão prontos para abate, com medida de aquisição de peso de 1,667 $\mathrm{kg}$ dia cada animal e obtendo $200 \mathrm{~kg}$ ao final dos 120 dias, conforme a Quadro 3.

Quadro 3 - Produtividade dos animais

\begin{tabular}{|r|r|r|r|r|r|r|r|r|}
\hline $\begin{array}{r}\text { Bovino } \\
\text { s }\end{array}$ & $\begin{array}{r}\text { Peso } \\
\text { em } \\
\text { Out }\end{array}$ & $\begin{array}{r}\text { Peso } \\
\text { em } \\
\text { Jan }\end{array}$ & $\begin{array}{r}\text { Peso } \\
\text { em } \\
\text { Fev }\end{array}$ & $\begin{array}{r}\text { Peso } \\
\text { em } \\
\text { Maio }\end{array}$ & $\begin{array}{r}\text { Peso } \\
\text { em } \\
\text { Junho }\end{array}$ & $\begin{array}{r}\text { Peso } \\
\text { em } \\
\text { Set }\end{array}$ & $\begin{array}{r}\text { Peso } \\
\text { Inicial }\end{array}$ & $\begin{array}{r}\text { Peso } \\
\text { Final }\end{array}$ \\
\hline 10 & 2.900 & 4.900 & 3.000 & 5.000 & 2.850 & 4.850 & 8.750 & 14.750 \\
\hline 1 & 290 & 490 & 300 & 500 & 285 & 485 & 291,67 & 491,67 \\
\hline
\end{tabular}

Fonte: dados dos registros contábeis

A produtividade de $200 \mathrm{~kg}$ por boi é alcançada na média geral entre os bovinos nas três safras, considerando os cento e vinte dias, necessários para ficarem prontos para abate, com gordura e rendimento de carcaça .

O preço do boi gordo para abate é definido pelo mercado do boi gordo, estabelecido em $\mathrm{kg} /$ vivo. Foram obtidos os seguintes preços em $\mathrm{kg} /$ vivo: em Janeiro $R \$ 2,00 / \mathrm{kg}$; em Maio $R \$ 1,9 / \mathrm{kg}$; e Setembro $R \$ 2,00 / \mathrm{kg}$, conforme evidenciado no Quadro 4.

Quadro 4 - Produtividade por safra

\begin{tabular}{|c|r|r|r|}
\hline $\begin{array}{l}\text { 10 Bois por } \\
\text { safra }\end{array}$ & Peso Total & Preço kg & Valor Total \\
\hline Janeiro & 4.900 & 2,00 & $9.800,00$ \\
\hline Maio & 5.000 & 1,95 & $9.750,00$ \\
\hline Setembro & 4.850 & 2,00 & $9.700,00$ \\
\hline Total & $\mathbf{1 4 . 7 5 0}$ & $\mathbf{1 , 9 8}$ & $\mathbf{2 9 . 2 5 0 , 0 0}$ \\
\hline
\end{tabular}

Fonte: elaborada pelos autores

O Quadro 4 evidencia que a propriedade obteve os seguintes valores brutos por animal:

a) em janeiro, novecentos e oitenta reais, 
b) em maio, novecentos e setenta e cinco reais,

c) em setembro, novecentos e setenta reais.

\subsubsection{LATICÍNIOS ZAMBAN LTDA}

O estudo realizado na fazenda Indústrias de Laticínios Zamban Ltda., Vacaria/RS. A fazenda tem como atividade rural a exploração agrícola, com plantação e comercialização de cereais e pecuária com a bovinocultura leiteira em sistema intensivo, com a produção e comercialização de leite e alguns subprodutos do leite.

O sistema intensivo na propriedade de estudo é, segundo a proprietária, a alternativa mais viável, pois, com o consórcio da agricultura e pecuária na propriedade, os outros sistemas inviabilizavam a rentabilidade das áreas de terras utilizadas pelas vacas leiteiras, onde segundo a proprietária a agricultura é mais rentável, comparada à bovinocultura leiteira em outros sistemas.

A mão-de-obra é composta por cinco funcionários que trabalham 8 horas por dia, ou seja, em tempo integral. Na atividade de produção do leite, as atividades ocupam o dia inteiro do funcionário. Além disso, exige mão-de-obra especializada.

Além disso, o sistema traz outros benefícios, como o aumento de produtividade e custos alimentares reduzidos, devido à junção com a agricultura explorada em áreas que seriam utilizadas pelas vacas em outros sistemas, que produz quase toda a alimentação necessária, como silagem, e resíduos provenientes da seleção de grãos produzidos na propriedade. Outros compostos alimentares adicionados à dieta das vacas, como minerais, sal e uréia que é um composto nitrogenado, no organismo dos bovinos transformam-se em proteína.

A dieta alimentar das vacas é orientada por médico veterinário. Esta dieta é balanceada e adicionada aos cochos, em média $4 \%$ do seu peso vivo, por vaca, conforme Quadro 5. 
Quadro 5 - Alimentação das vacas leiteiras

\begin{tabular}{|c|r|r|r|r|}
\hline $\begin{array}{r}\text { Alimentação } \\
\text { anual das } \\
\text { vacas }\end{array}$ & $\begin{array}{r}\text { Total em Kg } \\
\text { anual }\end{array}$ & $\mathbf{\%}$ & $\begin{array}{c}\text { Preço em } \\
\text { Kg }\end{array}$ & Custo total \\
\hline Silagem & 32.400 & 45 & 0,0187 & 607,14 \\
\hline Resíduo & 38.016 & 52,8 & 0,20 & 7.603 \\
\hline Minerais & 576 & 0,80 & 1,10 & 633,60 \\
\hline Uréia & 720 & 1 & 0,59 & 424,80 \\
\hline Sal & 288 & 0,4 & 0,32 & 92,16 \\
\hline Total & $\mathbf{7 2 . 0 0 0}$ & $\mathbf{1 0 0}$ & $\mathbf{0 , 1 3}$ & $\mathbf{9 . 3 6 0 , 9 0}$ \\
\hline
\end{tabular}

Fonte: dados dos registros contábeis

O alimento necessário para manutenção das vacas e conversão em leite é composto de uma dieta rigorosa, pois se a dieta for mal balanceada pode alterar algumas propriedades do leite, diminuir a produção ou desperdiçar alimentos.

A produção de leite da propriedade, objeto de estudo deste trabalho é de vinte e seis litros de leite em média anual por vaca, sendo que o período de lactação (meses em que as vacas produzem leite) é de duzentos e setenta (270) dias, produzindo em média setecentos e dois (702) litros de leite anuais, com um preço médio de mercado de cinqüenta e um $(0,51)$ centavos o litro, conforme Quadro 6.

Quadro 6 - Produção de leite

\begin{tabular}{|r|r|r|c|r|r|}
\hline $\begin{array}{r}\text { Vac } \\
\text { as } \\
\text { lactação/ } \\
\text { ano }\end{array}$ & $\begin{array}{r}\text { Produção } \\
\text { de leite } \\
\text { por vaca } \\
\text { (litros) }\end{array}$ & $\begin{array}{r}\text { Produção } \\
\text { total de } \\
\text { leite } \\
\text { (litros) }\end{array}$ & $\begin{array}{r}\text { Média } \\
\text { litro } \\
\text { leite } / \\
\mathrm{R} \$\end{array}$ & $\begin{array}{r}\text { Receita bruta } \\
\text { em R\$ do leite } \\
\text { por vaca }\end{array}$ & $\begin{array}{r}\text { Receita bruta } \\
\text { do leite em R\$ } \\
\text { no ano }\end{array}$ \\
\hline 10 & 7.020 & 70.200 & 0,51 & $3.580,20$ & $35.802,00$ \\
\hline
\end{tabular}

Fonte: dados dos registros contábeis

A média de litros de leite por vaca é medida dentro do período de lactação, e o preço médio do mercado durante o período. 


\subsection{APRESENTAÇÃO DOS RESULtAdOS DAS ATIVIDADES DE CADA CASO}

Os custos de produção da bovinocultura de corte demonstram que o custo mais significativo é o de aquisição de animais, que representam em torno de $79,85 \%$ e posteriormente os custos com despesas gerais em torno de $6,70 \%$ e alimentação em torno de 6,12 \% conforme Quadro 7.

Quadro 7 - Custo de produção do gado de corte

\begin{tabular}{|r|r|r|r|r|}
\hline CUSTOS DE PRODUÇÃO & Unidade & $\begin{array}{r}\text { Valor/ } \\
\text { UA }\end{array}$ & $\begin{array}{r}\text { Valor } \\
\text { total }\end{array}$ & $\mathbf{\%}$ \\
\hline NOVILHO & $\mathrm{kg}$ & 476,25 & $14.287,50$ & 79,85 \\
\hline MÃO-DE-OBRA & horas & 18,35 & 550,72 & 3,08 \\
\hline ALIMENTAÇÃO & $\mathrm{kg}$ & 65,80 & $1.094,28$ & 6,12 \\
\hline VETERINARIO & horas & 1,00 & 30 & 0,17 \\
\hline VEMIFUGOS & dose & 2,16 & 64,80 & 0,36 \\
\hline CARRAPATICIDAS & aplicação & 0,25 & 7,50 & 0,04 \\
\hline VACINA DA AFTOSA & dose & 1,25 & 37,50 & 0,21 \\
\hline VACINA DO CARBUNCULO & dose & 1,00 & 30,00 & 0,17 \\
\hline VACINA DA TUBERCULOSE & dose & 1,00 & 9,00 & 0,05 \\
\hline MODIFICADOR ORGÂNICO & dose & 0,20 & 6,00 & 0,03 \\
\hline IMPOSTOS & km² & 0,05 & 1,50 & 0,01 \\
\hline COMBUSTÍVEL & litros & 2,00 & 60,00 & 0,33 \\
\hline TELEFONE & ligação & 0,50 & 15,00 & 0,08 \\
\hline DEPRECIAÇÃO & km² & 10,00 & 300,00 & 1,68 \\
\hline MANUTENĈ̃̃ DE & benfeitorias & 6,67 & 200,00 & 1,12 \\
\hline EQUIPAMENTOS & & & & \\
\hline DESPESAS GERAIS & RATEIO & 120 & 1.200 & 6,70 \\
\hline TOTAIS & & $\mathbf{5 9 6 , 4 6}$ & $\mathbf{1 7 . 8 9 3 , 8 0}$ & $\mathbf{1 0 0}$ \\
\hline
\end{tabular}

Fonte: dados dos registros contábeis

Os custos de produção de mão-de-obra e veterinário são rateados por horas de trabalho executados na atividade, os insumos agropecuários foram rateados conforme foram aplicados em UA (Unidade Animal), em dose única ou periódica.

Os custos de depreciação, alguns impostos como ITR (Imposto Sobre a Propriedade Territorial Rural), CCR (Certificado de cadastro de imóvel rural), 
FARSUL (Federação da Agricultura do Estado do Rio Grande do Sul), são rateados conforme a área e instalações ocupadas pelos bovinos confinados, o imposto FR (Fundo Rural) é calculado no momento de venda dos bois. Os custos com combustível foram rateados por todos os animais da propriedade, e o telefone é relacionado pelas ligações efetuadas para desenvolvimento da atividade objeto deste estudo.

Quadro 8 - Custo de produção do gado leiteiro

\begin{tabular}{|c|c|c|c|c|}
\hline $\begin{array}{l}\text { CUSTOS DE } \\
\text { PRODUÇÃO }\end{array}$ & Unidade & VIr UA & VIr total & $\%$ \\
\hline INSEMINAÇÃO & dose & 60 & 600 & 2,70 \\
\hline MÃO-DE-OBRA & horas & 537,03 & $5.370,30$ & 24,15 \\
\hline ALIMENTAÇÃO & $\mathrm{kg}$ & 936,09 & $9.360,90$ & 42,09 \\
\hline VETERINÁRIO & hora & 60,00 & 600,00 & 2,70 \\
\hline VERMÍFUGOS & dose & 0,36 & 36 & 0,16 \\
\hline CARRAPATICIDAS & Aplicação & 0,25 & 2,50 & 0,01 \\
\hline VACINA DA AFTOSA & dose & 1,25 & 12,50 & 0,06 \\
\hline $\begin{array}{r}\text { VACINA DO } \\
\text { CARBÚNCULO }\end{array}$ & dose & 1,00 & 10,00 & 0,05 \\
\hline $\begin{array}{r}\text { VACINA DA } \\
\text { TUBERCULOSE }\end{array}$ & dose & 0,30 & 3,00 & 0,01 \\
\hline $\begin{array}{r}\text { MODIFICADOR } \\
\text { ORGÂNICO }\end{array}$ & dose & 0,20 & 2,00 & 0,008 \\
\hline IMPOSTOS & $\mathrm{km}^{2}$ & 0,15 & 1,50 & 0,007 \\
\hline COMBUSTÍVEL & litros & 10,00 & 100,00 & 0,45 \\
\hline TELEFONE & ligação & 6,50 & 65,0 & 0,292 \\
\hline MATERIAL DE LIMPEZA & aplicação & 6,90 & 69,00 & 0,31 \\
\hline $\begin{array}{r}\text { MATERIAL DE } \\
\text { ESTERILIZAÇÃO }\end{array}$ & aplicação & 122,85 & $1.228,50$ & 5,52 \\
\hline LUZ & $\mathrm{kw}$ & 153,78 & $1.537,85$ & 6,91 \\
\hline DEPRECIAÇÃO & benfeitorias & 122,54 & $1.225,40$ & 5,51 \\
\hline $\begin{array}{r}\text { MANUTENÇÃO DE } \\
\text { MÁQUINAS E } \\
\text { EQUIPAMENTOS }\end{array}$ & benfeitorias & 81,69 & 816,93 & 3,673 \\
\hline DESPESAS DIVERSAS & rateio & 120 & 1.200 & 5,39 \\
\hline TOTAL & & $2.224,14$ & $22.241,38$ & 100 \\
\hline
\end{tabular}

Fonte: dados dos registros contábeis 
Os custos de produção do leite, conforme Quadro 7, demonstram que os custos mais relevantes são os de alimentação com 42,09\% e de mão-de-obra $24,15 \%$, pois a bovinocultura leiteira requer funcionários dedicados exclusivamente para esta atividade, conforme Quadro 8.

Os custos de produção referentes à inseminação e insumos agropecuários foram alocados conforme aplicação dos mesmos, em dose única ou periódica.

Os custos com mão-de-obra foram rateados por UA (unidade animal) como manutenção de máquinas e equipamentos, depreciações, luz, material de limpeza e esterilização, telefone, combustível, veterinário, impostos. As dietas alimentares foram calculadas com base no custo do $\mathrm{kg}$ e multiplicado pela quantidade ingerida por animal no ano.

\subsection{ANÁLISE GERAL DOS RESULTADOS}

As atividades pecuárias de corte e leiteira possuem percentuais de custos diferentes.

Mesmo que se tratem das mesmas finalidades produtivas, seus custos diferem como pode ser visualizado no Quadro 9.

Quadro 9 - Custos comparativos das atividades pecuárias de corte e leite

\begin{tabular}{|r|r|r|r|r|}
\hline & \multicolumn{2}{|c|}{ Gado de Corte } & \multicolumn{2}{c|}{ Gado Leiteiro } \\
\hline Custos/produção & Valor & $\mathbf{\%}$ & Valor & \% \\
\hline Novilho & $14.287,50$ & 79.85 & - & - \\
\hline Mão-de-obra & 550,72 & 3,08 & $5.370,30$ & 24,14 \\
\hline Alimentação & $1.094,28$ & 6,112 & $9.360,90$ & 42,09 \\
\hline Veterinário & 30,00 & 0,17 & 1.200 & 5,395 \\
\hline Insumos Agropecuários & 154,80 & 0,86 & 66,00 & 0,30 \\
\hline Impostos & 1,50 & 0,008 & 1,50 & 0,006 \\
\hline Custos de manutenção & 275,00 & 1,54 & $3.817,28$ & 17,164 \\
\hline Depreciação & 300,00 & 1,68 & $1.225,40$ & 5,51 \\
\hline Despesas gerais & $1.200,00$ & 6,70 & 1.200 & 5,395 \\
\hline Total & $\mathbf{1 7 . 8 9 3 , 8 0}$ & $\mathbf{1 0 0}$ & $\mathbf{2 2 . 2 4 1 , 3 8}$ & $\mathbf{1 0 0}$ \\
\hline
\end{tabular}

Fonte: dados dos registros contábeis 
Os custos de produção apresentam percentuais com representatividades diferentes. Os custos de alimentação, mão-de-obra e custos de manutenção são mais representativos na bovinocultura leiteira. Enquanto os custos de aquisição de novilhos é o mais significativo, abrangendo $79,85 \%$ dos custos da bovinocultura de corte.

As demonstrações do resultado operacional das bovinoculturas de corte e leite objeto de estudo deste trabalho, apresentam resultados positivos em ambas as atividades, conforme Quadro 10.

Quadro 10 - Discriminação das receitas e custos

\begin{tabular}{|l|c|c|c|c|c|}
\hline CORTE & $\begin{array}{c}\text { Total } \\
\text { anual }\end{array}$ & $\%$ & LEITE & $\begin{array}{c}\text { Total } \\
\text { anual }\end{array}$ & $\%$ \\
\hline RECEITA BRUTA & 29.250 & 100 & $\begin{array}{c}\text { RECEITA } \\
\text { BRUTA }\end{array}$ & 35.802 & 100 \\
\hline $\begin{array}{l}\text { CUSTOS DE } \\
\text { PRODUÇÃO }\end{array}$ & $17.893,80$ & 61,17 & & $22.241,38$ & 62,12 \\
\hline $\begin{array}{l}\text { MARGEM DE } \\
\text { CONTRIBUIÇÃO } \\
\text { BRUTA }\end{array}$ & $11.356,18$ & 38,83 & & $13.560,62$ & 37,88 \\
\hline
\end{tabular}

Fonte: dados dos registros contábeis

A margem de contribuição da bovinocultura de corte é 0,95 pontos percentuais a mais que a bovinocultura leiteira. A lucratividade na pecuária depende de vários fatores, onde um deles é a produtividade, que impulsionou uma lucratividade maior na bovinocultura leiteira de 19,32\%.

Os impostos relativos à extensão territorial foram rateados conforme o espaço ocupado pelos animais. Nas empresas pesquisadas Amor à Terra e Zamban Ltda. o espaço delimitado foi de $10,000 \mathrm{~m}^{2}$ cujos valores foram os mesmos por coincidência. 


\section{CONSIDERAÇÕES FINAIS}

A pecuária é uma atividade rural muito antiga e ao longo dos tempos vem aprimorando-se. As bovinoculturas de corte e leiteira, foram divididas em bovinos de raças apropriadas, com objetivo de aumentar e melhorar a produção de carne e leite.

As atividades rurais, como a agricultura, também evoluiu trazendo benefícios à pecuária, como desenvolvimento de alimentos aos bovinos a baixo custo e viabilizando sistemas de produção evoluídos como o implantado nas empresas objeto de estudo deste trabalho. O sistema intensivo de produção é um sistema que proporciona maior e melhor produtividade por animal em áreas terrestres menores, porém eleva os custos de produção comparados a outros sistemas, como o semi-intensivo e extensivo.

As inovações nas atividades são reflexos do empenho dos produtores rurais, que por alguma razão, promoveram novas técnicas em suas propriedades. As novas técnicas compreendem a vários fatores como sistemas de produção, raças melhoradas geneticamente ou por cruza e gestão de negócios.

Atribui-se a gestão de negócios rurais a informação contábil. A ciência contábil conhece os desdobramentos econômicos e financeiros além do funcionamento da empresa. Através das ferramentas contábeis podem auxiliar em tomada de decisões, informar se as atividades são lucrativas ou não e quais contas são mais representativas em cada atividade.

Analisando as bovinoculturas de corte e leiteira em sistema intensivo, pode-se verificar que ambas as bovinoculturas são lucrativas e consorciadas podem trazer benefícios aos produtores rurais, como capital de giro e redução de custos, pois os insumos, instalações e alimentos são em grande parte os mesmos e a receita em consorcio das atividades deixa de ser trimestral, para mensal, ou pode auxiliar com valores acumulados ao trimestre para investimentos. 
NUNES, N.J.F. et al. A lucratividade na pecuária: atividades de bovinocultura de corte e de leite. PUBVET, Londrina, V. 6, N. 26, Ed. 213, Art. 1417, 2012.

Comparando os resultados de lucratividade destas atividades pecuárias num período de um ano verificou-se que a bovinocultura leiteira é mais lucrativa $19,32 \%$ que a bovinocultura de corte.

As bovinoculturas de corte e leiteira devem ser comparadas como indústrias de grande potencial de lucratividade, pois produzem produtos e geram renda, têm potencial de crescimento, utilizam-se tecnologia avançada e necessitam de informações contábeis para uma boa gestão do negócio agropecuário.

\section{REFERÊNCIAS BIBLIOGRÁFICAS}

ANGUS.2006. Disponível em: http://www.angus.org.br/raca/apresentacao.php. Acesso em: 05 nov 2006.

BANET. 2006. Disponível em: www.banet.com.br. Acesso em: 15 set. 2006.

BELLO, José Luiz de Paiva. Metodologia Científica: Pedagogia em Foco. Rio de Janeiro: s/e, 2004.

BISQUERA, R. Métodos de Investigação Educativa: Guia Prático. Barcelona: Ediciones CEAC, S. A, 1989.

BOVINOS. In: ENCARTA: Enciclopédia. [São Paulo]: Versão 2000. CD-ROM

CEPEA. 2006. Disponível em : www.cepea.esalq.usp.br Acesso em 08 set. 2006.

CORRÊA, Sílvio et al. Anuário Brasileiro da Pecuária / 2006. Santa Cruz do Sul: Gazeta Santa Cruz, 2006.

CREPALDI, Silvio Aparecido. Contabilidade rural: uma abordagem decisorial. 2. ed. rev., atual. e ampliada. São Paulo: Atlas, 1998.

CRIAPLANTAR. 2006. Disponível em: www.criareplantar.com.br. Acesso em: 23 out. 2006.

DIEHL, Astor Antônio; PAIM, Denise Carvalho Tatim. Metodologia e técnica de Pesquisa em Ciências Sociais. Passo Fundo: Clio Livros, 2002.

DIEHL, Astor Antônio. Pesquisa em ciências sociais aplicada: métodos e técnicas. São Paulo: Prentice Hall, 2004.

EUCLIDES FILHO, K. O composto de Bos taurus. Adaptação: Embrapa Gado de Corte. In: NEPOMUCENO, Fernando. Contabilidade rural e seus custos de produção. São Paulo: IOB Thomson, 2004.

GADOHOLANDES. 2006. Disponível em: http://www.gadoholandes.com.br. Acesso em: 14 set. 2006 
GIL, Antonio Carlos. Como elaborar Projetos de Pesquisa. 3.ed. São Paulo: Atlas S.A., 1991.

HISTÓRIANET. 2006. Disponível em: http://www.historianet.com.br Acesso em 25 de setembro de 2006

INSTITUTO Brasileiro de Geografia e Estatísticas - IBGE: banco de dados. Disponível em: www.ibge.gov.br. Acesso em: 14 set. 2006.

MARION, José Carlos. Contabilidade da Pecuária. 7 ed. São Paulo: Editora Atlas, 2004.

MINAYO, Maria Cecília de Souza (organizadora). Pesquisa Social: teoria, método e criatividade. 21.ed. Petrópolis: Vozes, 2002.

NEPOMUCENO, Fernando. Contabilidade Rural e seus Custos de Produção. São Paulo: IOPB Thomson, 2004.

PECUÁRIA 2000: PERSPECTIVAS PARA O III MILÊNIO, 2000, Pirassununga. Anais. Pirassununga: FZEA-USP, jun. 2000. CD-ROM. Palestras.

PECUÁRIA. Disponível em: http://pt.wikipedia.org/wiki/Pecu\%C3\%A1ria. Acesso em 05 de set. 2006.

RIOGRANDE. 2006. Disponível em: http://www.riogrande.com.br _Acesso em: 20 set. 2006.

VIANNA, Túlio Lima. Roteiro didático de elaboração de projetos de pesquisa em Direito 